\title{
Relation between antithrombin III and clinical and serological parameters in systemic lupus erythematosus
}

\author{
MARK P JARRETT, * DAVID GREEN, $\dagger$ CHUNG-HSIN TS'AO \\ From * Section of Arthritis-Connective Tissue Disease and the $\dagger$ Atherosclerosis Program, Department of \\ Medicine, and the $¥$ Department of Pathology, Northwestern University Medical School, Northwestern \\ Memorial Hospital and the Rehabilitation Institute, Chicago, Illinois, USA
}

SUMMARY The increased frequency of thromboembolic events in patients with systemic lupus erythematosus (SLE) has been attributed to reduced or dysfunctional antithrombin III (At-III). We analysed At-III values, measured by three different assay techniques, in SLE patients, patients with rheumatoid arthritis, and normal and hospitalised controls. In addition, attempts were made to correlate At-III activities of SLE patients with specific clinical and serological parameters such as disease activity, renal involvement, previous thrombosis, degree of proteinuria, and serum complement concentrations. Our results failed to show a significantly reduced At-III in SLE with any method. At-III titres did not correlate with disease activity, concentrations of serum complement or albumin (both only minimally reduced in most patients), or a previous history of thrombosis. At-III deficiency does not appear to be an inherent feature of SLE, and reduced activities should only be anticipated when there are specific aetiological factors present, such as massive proteinuria, extensive hepatic disease, or active thrombosis.

The activity of antithrombin III (At-III) has been shown to be highly correlated with a thrombotic diathesis. Congenital deficiency of this protein is associated with recurrent episodes of arterial and venous thrombosis. ${ }^{1-6}$ Acquired deficiency is found in a number of disease states. ${ }^{7-11}$ Systemic lupus erythematosus (SLE) is associated with an increased risk of thromboembolic complications, even in the presence of thrombocytopenia and circulating anticoagulants. ${ }^{12} 13$ Two recent studies described reduced, ${ }^{14}$ or functionally abnormal but immunologically normal ${ }^{15}$ At-III in this disease. Earlier, Angles-Cano et $a l^{16}$ reported normal activities of At-III in SLE. In order to gain further insight into the At-III activities in SLE and their possible variation with disease activity and medication, we determined At-III in a group of SLE patients, using both functional and immunological techniques. Hospitalised non-connective tissue disease patients and

Dr Jarrett's current address: 1460 Victory Boulevard, Staten Island, NY 10301, USA.

Accepted for publication 30 September 1982 patients with rheumatoid arthritis (RA) were studied concomitantly.

\section{Subjects and methods}

\section{SUBJECTS}

Normal subjects

Plasma samples from healthy volunteers of both sexes were used to establish standard curves and to obtain normal At-III values. Sixteen subjects were examined with functional assays and 25 with an immunological method. None of the women donors was taking oral contraceptives for at least one month prior to assay, and none was pregnant.

\section{SLE patients}

Thirty-one samples were obtained from 26 patients with SLE who met at least four criteria of the American Rheumatism Association. The group consisted of 24 women and 2 men; 22 were white and four black. Their mean age was $37 \pm 13$ yr. None of the female patients was taking oral contraceptives. Types of medication, serum complement concentrations, serum albumin, presence of renal disease or protein- 
uria, and previous history of thromboembolic diseases were recorded.

\section{$R A$ patients}

Fifteen patients with definite or classical rheumatoid arthritis (10 women; 13 white and two black) were also studied. Their mean age was $58 \pm 9 \mathrm{yr}$. Twelve of the patients were rheumatoid factor-positive. Thirteen patients were taking non-steroidal antiinflammatory agents, five on gold, four on penicillamine, three on hydroxycholoraquine, and one on azathioprine.

\section{Hospitalised patients}

Twenty-eight consecutive hospitalised patients had their At-III activities determined as part of their diagnostic evaluation.

\section{BLOOD SAMPLING}

Blood, drawn into citrate-containing vacutainers (Becton-Dickinson, Rutherford, NJ), was centrifuged at $1100 \mathrm{~g}$ for $15 \mathrm{~min}$ at $4^{\circ} \mathrm{C}$. The supernatant plasma was frozen at $-20^{\circ} \mathrm{C}$ and assayed for At-III within 2 wk.

\section{AT-III ASSAYS}

\section{Amidolytic assay}

The assay is based on the inhibition by diluted plasma of the hydrolysis of a fluorogenic synthetic substrate (D-phenylalanine-proline-arginine-5aminoisophthalic acid, dimethylester) by a known amount of thrombin in the presence of optimal concentrations of heparin. ${ }^{17}$ Reagents for this assay $\stackrel{0}{\vec{*}}$ were purchased from the American Dade Corpora-. . tion, (Miami, Florida). Standard curves were not $\vec{F}$ required for the amidolytic assay. At the beginning of $\frac{\text { ? }}{9}$ each run, the fluorometer (Protopath, American Dade Corp) was calibrated with a solid reference $\frac{\bar{c}}{\mathrm{c}}$ standard. Then, measurements were made with a $\vec{\Phi}$

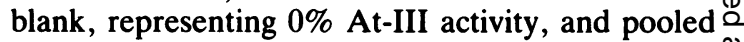
normal human plasma (PNP), representing $100 \%$ क activity. At-III activities in test plasma were cal- $\overrightarrow{0}$ culated according to the formula:

$$
\begin{aligned}
& \% \text { thrombin inhibited }=\frac{\text { blank reading }- \text { PNP reading }}{\text { blann reading }} \times 100 \\
& \% \text { At-III test plasma }=\frac{\text { \% thrombin inhibied by test plasma }}{\% \text { thrombin inhibitied by PNP }}
\end{aligned}
$$

\section{Anticlotting assay}

This was a two stage assay. Stage 1 involved neutralisation of a quantity of known thrombin by At-III in defibrinated $\left(56^{\circ} \mathrm{C}, 5 \mathrm{~min}\right)$ test plasma. In stage 2 , the neutralised sample was mixed with ${ }_{-}^{-}$ human fibrinogen and the clotting time determined. The longer the clotting time, the higher the At-III activity in the defibrinated plasma.$^{18}$ Reagents for this assay were obtained from Ortho Diagnostics Inc $\mathscr{C}_{\infty}$ (Raritan, New Jersey). Standard curves for the assay were established with each kit of reagents, using standard human plasma provided with the kit.

\section{Immunological assay}

The technique of rocket electroimmunoassay was $\stackrel{\circ}{\mathbb{D}}$ used. ${ }^{19}$ The personnel who performed these tests had $\underset{\vec{F}}{\overrightarrow{7}}$ no knowledge of the functional assay results. At-III

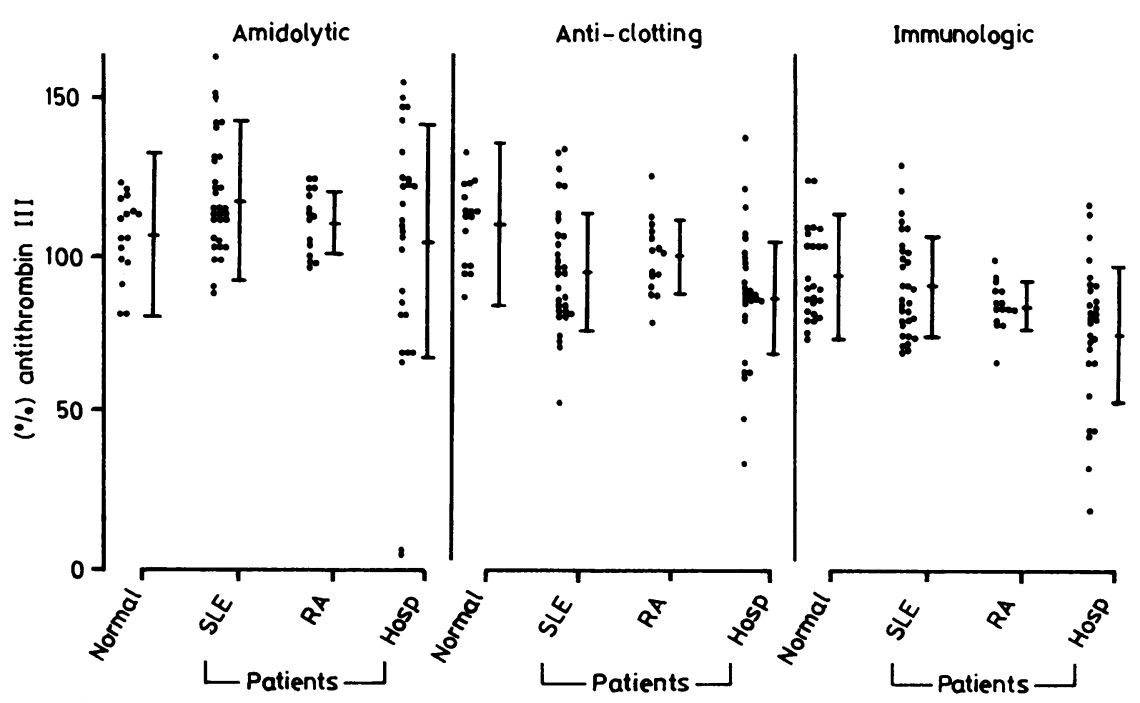

Antithrombin III activities of individuals determined by three assay techniques. Bars indicate mean and standard deviation for each group of subjects 
Comparison of At-III activities in SLE patients with or without certain clinical and serological manifestations

\begin{tabular}{|c|c|c|c|c|c|c|c|c|c|c|c|c|}
\hline & \multicolumn{4}{|c|}{ Disease activity } & \multicolumn{2}{|c|}{ Proteinuria } & \multicolumn{2}{|c|}{$\begin{array}{l}\text { Serum } \\
\text { complement }\end{array}$} & \multicolumn{2}{|c|}{$\begin{array}{l}\text { Renal } \\
\text { involvement }\end{array}$} & \multicolumn{2}{|c|}{$\begin{array}{l}\text { Previous } \\
\text { thrombosis }\end{array}$} \\
\hline & 0 & + & ++ & +++ & Neg. & Pos. & Nor. & Dec. & Neg. & Pos. & Neg. & Pos. \\
\hline $\begin{array}{l}{ }^{*} \text { At-III Mean } \pm \text { SD }(\%) \\
\text { †At-III Mean } \pm \text { SD }(\%) \\
\text { No of patients }\end{array}$ & $\begin{array}{l}122 \cdot 8 \\
\pm \\
22 \cdot 6 \\
85 \cdot 8 \\
\pm \\
13 \cdot 5 \\
10\end{array}$ & $\begin{array}{l}119 \cdot 3 \\
\pm \\
17 \cdot 5 \\
95 \cdot 7 \\
\pm \\
15 \cdot 9 \\
9\end{array}$ & $\begin{array}{l}115 \cdot 8 \\
\pm \\
10 \cdot 3 \\
86 \cdot 3 \\
\pm \\
15 \cdot 9 \\
4\end{array}$ & $\begin{array}{l}111 \cdot 7 \\
\pm \\
10 \cdot 6 \\
91 \cdot 0 \\
\pm \\
8 \cdot 6 \\
3\end{array}$ & $\begin{array}{l}114 \cdot 2 \\
\pm \\
15 \cdot 0 \\
88 \cdot 1 \\
\pm \\
15 \cdot 3 \\
21\end{array}$ & $\begin{array}{l}138 \cdot 8 \\
\pm \\
20 \cdot 7 \\
98 \cdot 4 \\
\pm \\
\frac{ \pm}{5} \cdot 0\end{array}$ & $\begin{array}{l}119 \cdot 7 \\
\pm \\
19 \cdot 2 \\
89 \cdot 7 \\
\pm \\
17 \cdot 5 \\
12\end{array}$ & $\begin{array}{l}118 \cdot 6 \\
\pm \\
19 \cdot 8 \\
90 \cdot 0 \\
\pm \\
13 \cdot 6 \\
14\end{array}$ & $\begin{array}{l}114 \cdot 5 \\
\pm \\
15 \cdot 9 \\
87 \cdot 7 \\
\pm \\
12 \cdot 2 \\
17\end{array}$ & $\begin{array}{l}132 \cdot 2 \\
\pm \\
20 \cdot 1 \\
90 \cdot 0 \\
\pm \\
15 \cdot 3 \\
9\end{array}$ & $\begin{array}{l}117 \cdot 8 \\
\pm \\
17 \cdot 7 \\
88 \cdot 1 \\
\pm \\
12 \cdot 9 \\
22\end{array}$ & $\begin{array}{l}137 \cdot 8 \\
\pm \\
17 \cdot 5 \\
94 \cdot 4 \\
\pm \\
16 \cdot 3 \\
4\end{array}$ \\
\hline
\end{tabular}

*Determined by an amidolytic assay.

†Determined by an immunologic assay.

antisera were purchased from Calbiochem-Behring Co (La Jolla, California). Standard curves for the assay were established using plasma pooled from 20 normal donors.

STATISTICAL ANALYSIS

Data were analysed by Student's $t$ test, the $\chi^{2}$ analysis and linear regression.

\section{Results}

Individual At-III activities of all four groups of subjects, and the means and standard deviations as determined by the three techniques are presented in the Figure. For both the normals and hospitalised patients, there was a significant correlation among At-III values assayed by these methods $(r=0.60, p<$ $0 \cdot 01$ ). In the SLE group, the two functional assays correlated with each other $(r=0.82, p<0.001)$, but neither correlated with the immunological assay $(r=$ $0.33, p>0 \cdot 10)$. In the RA group, either functional assay correlated with the immunological assay $(r=$ $0.71, p<0.001$ ), but there was no correlation between the functional assays $(r=0 \cdot 16, p>0 \cdot 10)$. Nevertheless, all values derived from the functional assays for RA patients were within the range of normal controls.

In determining whether there might be a positive relation between At-III activities and specific clinical problems in SLE patients, we compared At-III values with various clinical and serological parameters. Results are shown in the Table. There was no correlation between disease activity $(0=$ no activity; $+++=$ active disease involving major organ systems) with either functional or immunological At-III activities. Only one patient with a low immunological value $(70 \%)$ had +++ disease activity. At-III values of 14 patients with reduced complement titres were comparable to the normocomplementaemic group. Nine patients with documented renal disease (active urinary sediment or positive renal biopsy), and 5 patients with proteinuria $(0.3$ to $5.9 \mathrm{~g} / 24 \mathrm{~h}$ urine $)$, had
At-III values similar to those without renal involvement or proteinuria. Furthermore, there was no correlation between serum albumin concentrations and At-III. Four patients with a history of thromboembolic disease also had normal levels of At-III. None of the SLE patients had active thromboembolic complications at the time of the assay. Some SLE patients were receiving prednisone (up to $60 \mathrm{mg} /$ day; mean dose of $10.5 \pm 15 \mathrm{mg} /$ day). There was a significant correlation between the steroid dose and immunological activities of At-III $(\mathrm{r}=0.63, \mathrm{p}<0.001)$.

One patient with RA had a low immunological AtIII $(66 \%)$. However, there were no unusual clinical or serological features in ihis patient, and she had no history of thromboembolic disease.

\section{Discussion}

At-III, an $\alpha_{2}$-globulin, is a major inhibitor of activated clotting factors, and is responsible for heparin cofactor activity. Deficiency of this globulin, either congenital or acquired, leads to a state of hypercoagulability. SLE is often associated with such a state. According to one report,,$^{13}$ almost $25 \%$ of the 35 SLE patients developed clinically significant thrombosis. Another report puts the figure around $10 \% .{ }^{20}$ The precise mechanism underlying the development of thrombosis in SLE is not clear. AnglesCano et $a l^{16}$ attributed this tendency to an increased factor VIII-related antigen level in plasma. On the other hand, the finding that some SLE patients with proteinuria showed reduced At-III titres, ${ }^{14}$ and one SLE patient had dysfunctional At-III, ${ }^{15}$ imply a quantitative or qualitative defect in At-III.

Because of the critical antithrombotic role of AtIII, we elected to re-examine the plasma activities of this protein in a group of SLE patients using three different assay techniques. Such a broad approach would provide us with a more accurate picture of AtIII values by minimising the shortcomings inherent in a single procedure. It is particularly warranted in 
light of reports of discrepant results obtained by functional and immunological techniques in SLE ${ }^{15}$ and in other diseases. ${ }^{21}{ }^{22}$ We also determined At-III titres in a group of rheumatoid patients to see whether the defect in At-III would be specific for SLE, or also be present in closely related connective tissue disorders. We assayed At-III in a group of hospitalised patients to ensure that each of the techniques we employed was capable of detecting reduced activities of At-III.

Statistically, our assay methods did not always correlate among themselves for all groups of subjects. Nevertheless, a sample showing reduced At-III by one method was usually low by another method. Within a given method, the mean At-III value for SLE patients was not significantly different from that of normal controls. In addition, with the exception of steroid intake, the At-III values of SLE patients appeared to have no relation to any of the clinical or serological parameters we measured, regardless of whether these values were obtained by an amidolytic or an immunological assay. It should be pointed out that none of our patients had active thrombosis at the time of the assay. The highest protein content in the urine of the five positive proteinuria patients was 5.9 $\mathrm{g} / 24 \mathrm{~h}$, far less than the protein concentrations in urine samples of most of the At-III deficient patients described by Kaufmann et al. ${ }^{11}$ None of our patients had serum albumin concentrations below $2.9 \mathrm{~g} / 1$. We therefore conclude that At-III deficiency does not appear to be an inherent feature of SLE. Reduced activities should probably be anticipated only when specific aetiological factors are present. These factors may include severe proteinuria, extensive hepatic disease and active thrombosis.

We thank Theresa S Galluzzo and Nancy Reynolds for their excellent technical assistance.

\section{References}

${ }^{1}$ Egeberg $O$. Inherited antithrombin deficiency causing thrombophilia. Thrombosis et Diathesis Haemorrhagica 1965;13:516-30.

${ }^{2}$ Van der Meer J, Stoepman-Van Dalen EA, Jensen JMS. Antithrombin III deficiency in a Dutch family. J Clin Pathol 1973;26:532-8.

${ }^{3}$ Carvalho A, Ellman L. Hereditary antithrombin III deficiency. Effect of antithrombin III deficiency on platelet function. Am J Med 1976;61:179-83.
${ }^{4}$ Marciniak E, Farley CH, DeSimone PA. Familiar thrombisis due to antithrombin III deficiency. Blood 1974;43:219-31.

${ }^{5}$ Mackie M, Bennett B, Ogston D, Douglas AS. Familiar

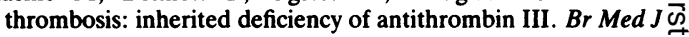
1978; i:136-8.

${ }^{6}$ Scully MF, De Haas H, Chan P, Kakkar VV. Hereditary $\frac{\bar{C}}{0}$ antithrombin deficiency in an English family. $\mathrm{Br} J$ Haematol $\overline{\bar{\omega}}$ 1981;47:235-40.

${ }^{7}$ Braunstein KM, Eurenius K. Minimal heparin cofactor activity in $\underset{\varnothing}{\varnothing}$ disseminated intravascular coagulation and cirrhosis. Am J Clin
Pathol 1976;66:488-94.

${ }^{8}$ Yue RH, Gertler MM, Starr T, Koutrowby R. Alteration of $\overrightarrow{0}$ plasma antithrombin III levels in ischemic heart disease. Thromb Haemost 1976;30:598-606.

${ }^{9}$ Innerfield I, Goldfisher JD, Reicher-Reiss H, Greenberg J. Serum antithrombin in coronary-artery disease. Am J Clin Pathot ㅇํㅇ 1976;65:64-8.

${ }^{10}$ Thaler E, Balzar E, Kopsa H, Pinggera WF. Acquired antithrombin III deficiency in patients with glomerular proteinuria. Haemostasis 1978;7:257-72.

${ }^{11}$ Kaufmann RH, Veltkamp JJ, Van Tilburg NH, Van Es LA. W Acquired antithrombin III deficiency and thrombosis in the nephrotic syndrome. Am J Med 1978;65:607-13.

12. Bowie EJW, Thompson JH, Pascuzzi CA, Owen CA. Thrombosis in systemic lupus erythematosus despite circulating $Z$ anticoagulants. J Lab Clin Med 1963;62:416-30.

${ }^{13}$ Mueh JR, Herbst KD, Rapaport SI. Thrombosis in patients with the lupus anticoagulant. Ann Intern Med 1980;92:156-9.

${ }^{14}$ Jarrett MP, Grayzel AI, Bonland P, Sussman I. Acquired $\vec{\bullet}$ antithrombin III deficiency and systemic lupus erythematosus. (Letter to the Editor). Ann Rheum Dis 1981;40:211.

${ }^{15}$ Cosgriff TM, Martin BA. Low functional and high antigenic antithrombin III level in a patient with the lupus anticoagulant and recurrent thrombosis. Arthritis Rheum 1981;24:94-6.

${ }^{16}$ Angles-Cano E, Sultan Y, Cluvel JP. Predisposing factors to thrombosis in systemic lupus erythematosus. J Lab Clin Med 1979;94:312-23.

${ }^{17}$ Mitchell GA, Hudson PM, Huseby RM, Pochron SP, Gargiulo RJ. Fluorescent substrate assay for antithrombin III. Thromb $\underline{0}$ Res 1978;12:219-25.

${ }^{18}$ Bick RL, Kovacs I, Fekete LF. A new two-stage functional assay for antithrombin III (heparin cofactor). Clinical and laboratoryo evaluation. Thromb Res 1976;8:745-56.

${ }^{19}$ Laurell CB. Quantitative estimation of protein by electrophoresis in agarose gel containing antibodies. Anal Biochem 1966;15:4552.

${ }^{20}$ Gladman DD, Urowitz MB. Venous syndromes and pulmonary. embolism in systemic lupus erythematosus. Ann Rheum Disô 1980;39:340-3.

${ }^{21}$ Sas G, Blasko G, Banhegyi D, Jako J, Palos LA. Abnormal antithrombin III (Antithrombin 'Budapest') as a case of a familiar thrombophilia. Thromb Haemost 1974;32:105-15.

${ }^{22}$ Sorensen PJ, Sas G, Peto I, Blasko G, Dremmer T, Samu A. 을 Distinction of two pathologic antithrombin III molecules: Antithrombin III 'Aalborg' and antithrombin III 'Budapest'. Thromb Res 1982;26:211-9.

Requests for reprints to: Professor C. Ts'ao, Department of ${ }_{0}$ Pathology, Northwestern Medical Center, Wesley Pavilion, East Superior Street and Fairbanks Court, Chicago, Illinois? 60611, USA. 